\title{
LOAD FREQUENCY CONTROL OF MULTI AREA INTERCONNECTED POWER SYSTEM USING DIFFERENTIAL EVOLUTION ALGORITHM
}

\author{
Alireza SINA, Damanjeet KAUR
}

\begin{abstract}
In this paper, Proportional Integral Derivative (PID) controller is designed using Differential Evolution (DE) algorithm to Load Frequency Control (LFC) in three areas of an interconnected power system. The proposed controller has appropriate dynamic response, so it increases damping in transient state in unhealthy conditions. Different generators have been used in three areas. Area 1 includes thermal non-reheat generator and two thermal reheat generators; area 2 includes hydro and thermal non-reheat generators, and area 3 includes hydro and thermal reheat generators. In order to evaluate the performance of the controller, Sim/Matlab software is used. Simulation results show that the controller designed using DE algorithm is not affected by load changes, disturbance, or system parameters changes. Comparing the results of proposed algorithm with other load frequency control algorithms, such as PSO and GA, it has been found that this method has a more appropriate response and satisfactory performance.
\end{abstract}

Keywords: ACE; DE; Frequency Deviation; LFC; Tie Line Power Deviation

\section{INTRODUCTION}

A modern power system has a number of generating units. These units are located in different areas. These areas are connected to each other with the help of a tie line to exchange power. When load change occurs in a modern power system, the balance between generated power and load is disturbed. This effect leads to a frequency deviation from the rated value, and the tie line power among different areas is changed from the scheduled value. If large deviations occur, power system may become unstable too.

For successful operation of power system, the balance between generated power and load demand should be maintained. In load frequency control (LFC) oscillations are damped and can maintain frequency and appropriate transient behaviour. Automatic generation control (AGC) includes load frequency control loop and an automatic voltage regulator (AVR) loop that regulates the frequency and power flow [1]. The main purpose of automatic generation control is to maintain frequency at rated value and tie line power at scheduled values when unusual conditions such as load changes, disturbance and system parameters change. For this purpose, intelligent control methods are developed to get the desired dynamic response.

In [2-7], intelligent techniques are used to optimize the PID / PI controller parameters. In [2], Laurent series is used to optimize the PID controller parameters. In [3], DE algorithm is used to design a 2-Dof PID (Parallel 2 degree freedom off) controller in for load frequency control in an interconnected power system. To eliminate frequency oscillations and tie line power, authors used SA (Simulated Annealing) algorithm for AVR [4]. In [5], direct synthesis method is used. In this method PID controller parameters are determined by linear algebraic equations. MUGA (Multi objective uniform diversity genetic algorithm) algorithm is implemented to optimize the PI/PID controller parameters [6]. In [8-14] PI/PID controller parameters are optimized using fuzzy logic in combination with intelligent techniques.
In [8] SAMA (Self-adaptive modified algorithm) algorithm along with fuzzy logic is used to obtain PI controller parameters. A type-2 fuzzy PID controller is designed via BBBC (Bing bang-big crunch) algorithm [9]. In this method, possible uncertainty in large-scale complex systems is considered and type-2 fuzzy sets are used. In order to optimize the PID controller parameters, GA, ANN and ANFIS algorithms are used [10]. Results show that the ANFIS algorithm has a more appropriate response. In [11], TBLO (Teaching learning based optimization) algorithm is used to obtain fuzzy PID controller parameters.

A hybrid combination of Neuro and Fuzzy is proposed as a controller to solve the Automatic Generation Control (AGC) problem in a restructured power system that operates under deregulation on the bilateral policy.

Recently evolutionary algorithms are used more often. Differential evolution (DE) is a method that repeats the attempt to find optimal points by differentiating a criterion. In classical optimization methods, such as gradient and Newton, a derivative operator is used, while in results of DE the quality criterion search method is used [15]. DE optimizes a problem by maintaining a population of candidate solutions and creating new candidate solutions by combining existing ones according to its simple formulae, and then keeping the candidate solution which has the best score or fitness on the optimization problem at hand. In this way, an optimization problem is treated as a black box that merely provides a measure of quality given by a solution, therefore the gradient is not needed.

In this paper, a PID controller is used for load frequency control in a three area interconnected power system. DE algorithm is used to optimize the controller parameters. By comparing the obtained results of simulations with other intelligent methods, including GA and PSO, the superiority of the proposed algorithm is specified. The impact of sudden load changes and system parameters changes is also considered in the proposed method. 


\section{THE SYSTEM MODEL}

A three-area power system as shown in Fig. 1 is considered to evaluate the proposed method. Different generation sources are used in each area. Area 1 includes thermal non-reheat and reheat generators, while areas 2 and 3 include hydro and thermal reheat. System parameters are defined in Tab. 1. The connection between different areas is shown in Fig. 1. The dynamic models of generators used in the simulations are explained in [16-18].

As occurrence of any disturbance in each area causes frequency changes in all areas and tie line power deviation from scheduled values. A PID controller is used in each area in order to quickly damp oscillations and to reduce the overshoot and undershoot values. DE algorithm is used to optimize the parameters. Controller input is $A C E$ signal. $A C E$ is a linear combination of tie line power frequency that can be defined for each area $i^{\prime}$ th as Eq. (1).

$$
A C E_{i}=\sum_{j} \Delta P_{t i e, i j}+\beta_{i} \Delta f_{i}
$$

In Eq. (1), $\Delta P_{t i e, i j}$ is the power exchange between areas $i$ and $j, \beta_{i}$ is basic frequency coefficient of area $i$ and $\Delta f_{i}$ is frequency deviation of area $i$. In a multi-area power system, $T_{i j}$ is considered as synchronizing coefficient between areas $i$ and $j$, and $\Delta p_{i}$ is also considered as load disturbances in area $i$.

\section{DESIGN OF CONTROLLER}

Differential Evolution (DE) technique is a populationbased heuristic optimization algorithm [14-15]. Benefits of $\mathrm{DE}$ are: Simpleness, efficiency, and real coding. Generally, the base of DE is Genetic Algorithm (GA). However, unlike simple GA that uses binary coding for representing problem parameters, DE uses real coding of floating point numbers. The crucial idea behind $\mathrm{DE}$ is a scheme for generating trial parameter vectors. Basically, DE works with two populations; old generation and new generation of the same population. It works through a simple cycle of stages as Fig. 2.

Stage 1: Initial Population

A population of fixed size to generated where each variable has its lower and upper bounds.

Stage 2: Mutation

Selection of vectors to a base individual in order to explore the search space.

$$
\begin{aligned}
& V_{i G+1}=X_{r 1 G}+F_{1}\left(X_{r 2 G}-X_{r 3 G}\right) \\
& V_{i G+1}=X_{\text {best } G}+F_{1}\left(X_{r 2 G}-X_{r 3 G}\right) \\
& V_{i G+1}=X_{r 1 G}+F_{1}\left(X_{r 2 G}-X_{r 3 G}\right)+F_{2}\left(X_{\text {best } G}-X_{r 1 G}\right)
\end{aligned}
$$

Where: $i=1, \ldots, N P ; r_{1}, r_{2}, r_{3} \in\{1, \ldots, N P\}$ are randomly selected and satisfy; $r_{1} \neq r_{2} \neq r_{3} \neq i ; \mathrm{F} \in[0,1], F$ is the control parameter/mutation factor proposed by Storn and Price [3].
Stage 3: Recombination or crossover

Mix successful solutions from the previous generation with current donors. The perturbed individual, $V_{i G+1}=\left(v_{1, i G+1}, \ldots\right.$, $\left.v_{n, i G+1}\right)$ and the current population member, $V_{i G}=\left(x_{1, i G}, \ldots\right.$, $\left.x_{n, i G}\right)$ are subject to the crossover operation, which finally generates the population of candidates, or "trial" vectors, $U_{i G+1}=\left(u_{1, i G+1}, \ldots, u_{n, i G+1}\right)$ as follows:

$U_{i, j G+1}=\left\{\begin{array}{lr}V_{i, j G+1} & \text { if } \text { rand }_{i, j} \leq C R \text { or } j=I_{\text {rand }} \\ X_{i, j G} & \text { otherwise }\end{array}\right.$

With rand $_{i, j} \sim U(0,1), I_{\text {rand }}$ is a random integer from (1, $2, \ldots, D)$ where $D$ is the solution's dimension, i.e. number of control variables and $\mathrm{CR} \in[0,1]$.

Stage 4: Selection

To keep the population size constant over subsequent generations, selection operation is performed. In this operation the target vector $X_{i G}$ is compared with the trial vector $V_{i G+1}$ and the one with the better fitness value is admitted to the next generation. The selection operation in DE can be represented by:

$X_{i G+1}=\left\{\begin{array}{lr}V_{i G+1} & \text { if } F\left(U_{i G+1}\right)<F\left(X_{i G}\right) \\ X_{i G} & \text { otherwise }\end{array}\right.$

Proportional integral derivative controller (PID) is one of the most popular feedback controllers in the process industries because of its stability and fast response.

Design of PID controller requires determination of the three main parameters, Proportional gain $K_{p}$, Integral gain $K_{i}$ and Derivative gain $K_{d}$. The integral square error (ISE) criterion is considered as the objective function for the present work which is described in Eq. (7).

$I S E=\int_{0}^{t_{s i m}}\left(\Delta f^{2}+\Delta P_{t i e}^{2}\right) \mathrm{d} t$

Where $\Delta f$ is the system frequency deviation in area- $i$ and area-j, respectively, $\Delta P_{\text {tie }}^{2}$ is the incremental change in tie line power and $t_{\text {sim }}$ is the time range of simulation. Fig. 3 shows flowchart of proposed DE and PID controller. The problem constraints are the controller parameter bounds. Therefore, the design problem can be formulated as the following optimization problem.

Minimum ISE. Subject to:

$K_{p \min } \leq K_{p} \leq K_{p \max }, K_{i \min } \leq K_{i} \leq K_{i \max }$ and $K_{d \min } \leq K_{d} \leq$ $K_{d \max } . K_{\min }, K_{\max }$ are the minimum and maximum value of the control parameters. The flowchart of the DE-PID algorithm is shown Fig. (3).

\section{THE SIMULATION RESULTS}

An interconnected power system includes three-area power system as shown in Fig. 1, which is simulated in $\mathrm{Sim} /$ Matlab software. System parameters have been defined according to the Tab. 1 and their values are shown in Tab. 2 . 
Power required in each area is considered to be $\Delta p_{L}=0.1 \mathrm{pu}$ MW. PID controller is used in each area for automatic generation control. The controller parameters are optimized using DE, PSO, and GA algorithms.

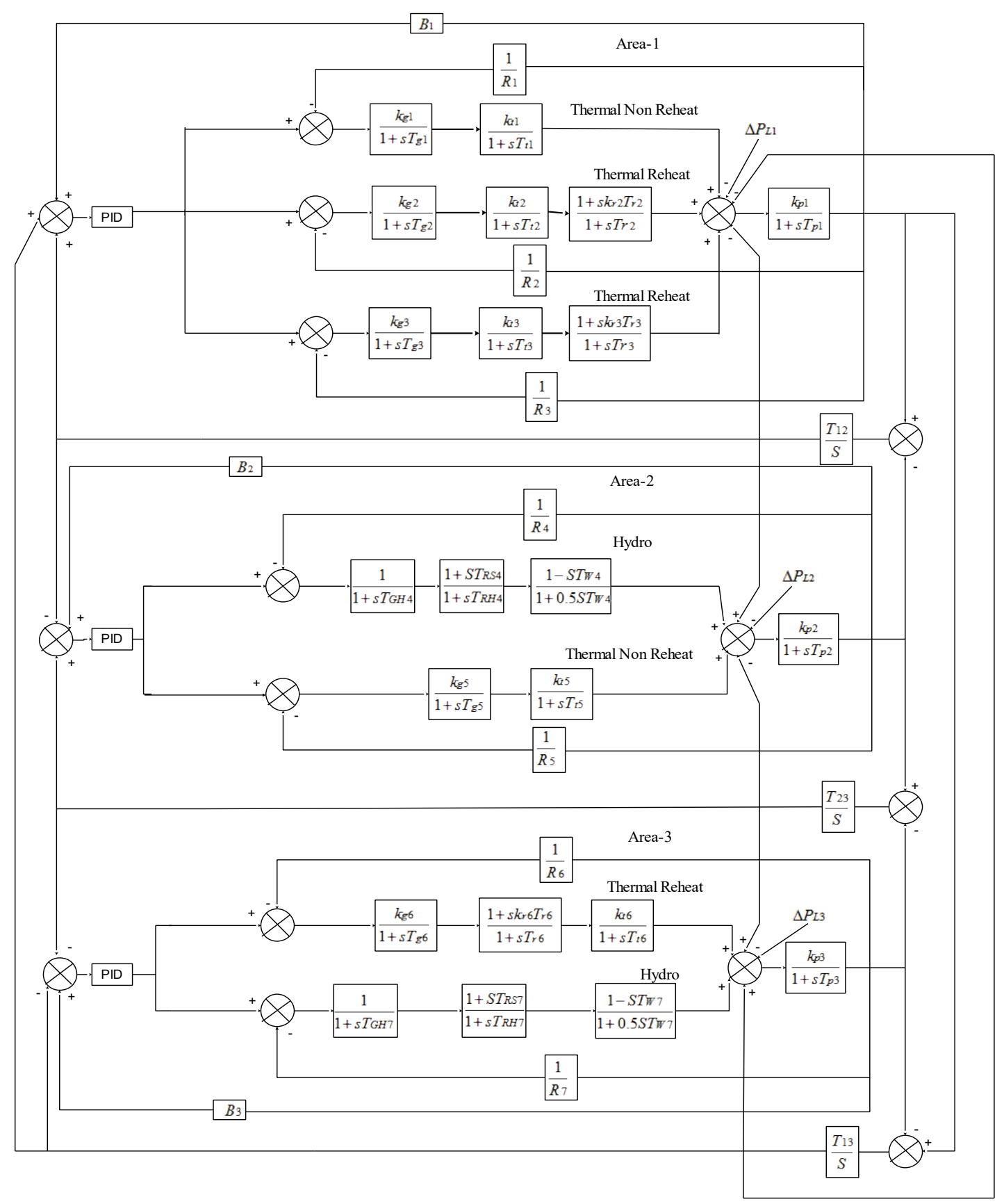

Figure 1 Three area multi source power system structure

Table 1 System parameters

\begin{tabular}{|c|l|c|l|}
\hline Nomenclature & \multicolumn{2}{l|}{} \\
\hline$A C E_{i}$ & Area control error of $i^{\text {th }}$ eara & $\Delta$ & Droop characteristic \\
\hline$F$ & Area frequency & $\Delta F_{i}$ & Incremental change in frequency of $i^{\text {th }}$ control area \\
\hline$B_{i}$ & Frequency bias constant of $i^{\text {th }}$ control area & TP & Subsystem equivalent time constant \\
\hline$T_{g}$ & Governer time constant & $K P$ & Subsystem equivalent gain constant \\
\hline$T_{t}$ & Turbine time constant & $T_{i j}$ & Synchronizing coefficient between area $i$ and $j$ \\
\hline$T_{r}$ & System turbine reheat time constant & $e p f k$ & Economic participation factor of $k^{\text {th }}$ generation unit \\
\hline$T G H$ & Hydro turbine speed governer main servo time constant & $c p f k$ & Constant participation factor between $k^{\text {th }}$ GENCO and $i^{\text {th }}$ DISCO \\
\hline$T R S$ & Hydro turbine speed governer reset time & $\Delta P_{t i e, i j}$ & Scheduled power tie line power flow between area $i$ and $j$ \\
\hline$T R H$ & Hydro turbine speed governer transient droop time constant & $\Delta P D_{i}$ & Total power control and uncontrolled for DISCO area $i^{\text {th }}$ \\
\hline$T W$ & Nominal starting time of water in penstock & $\Delta P_{g k}$ & Power output of $k^{\text {th }}$ generating unit \\
\hline
\end{tabular}




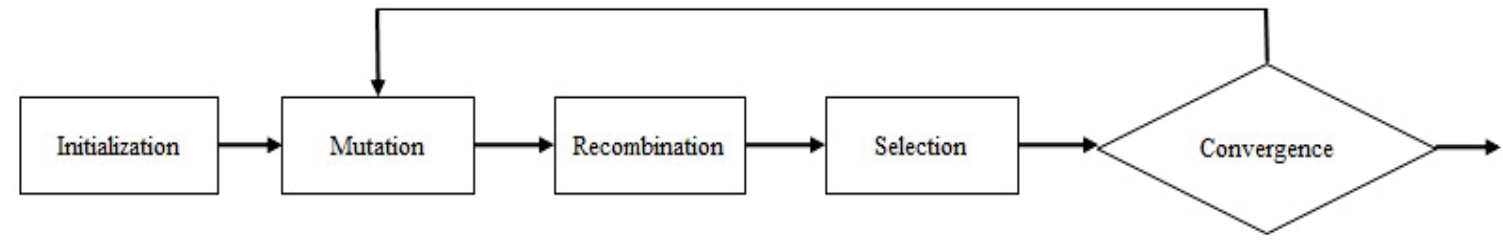

Figure 2 Simple cycle of DE

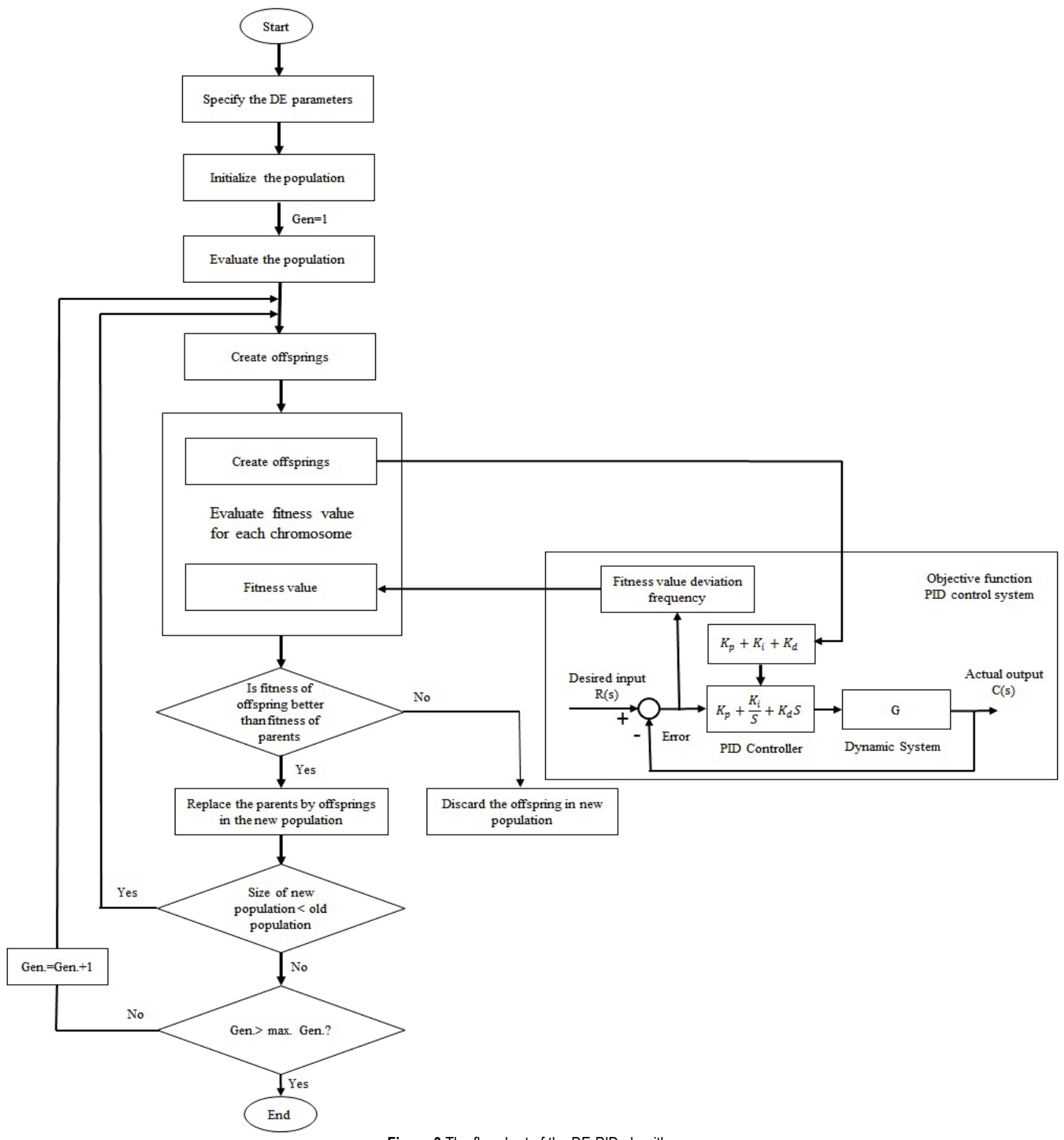

Figure 3 The flowchart of the DE-PID algorithm

Figs. 4 and 5 show the dynamic response of the system frequency deviation and tie-line power exchange between different areas respectively, in present of DE, PSO and GA algorithms. From Figs. 4 and 5 it is clear that overshoot and undershoot is minimal. 

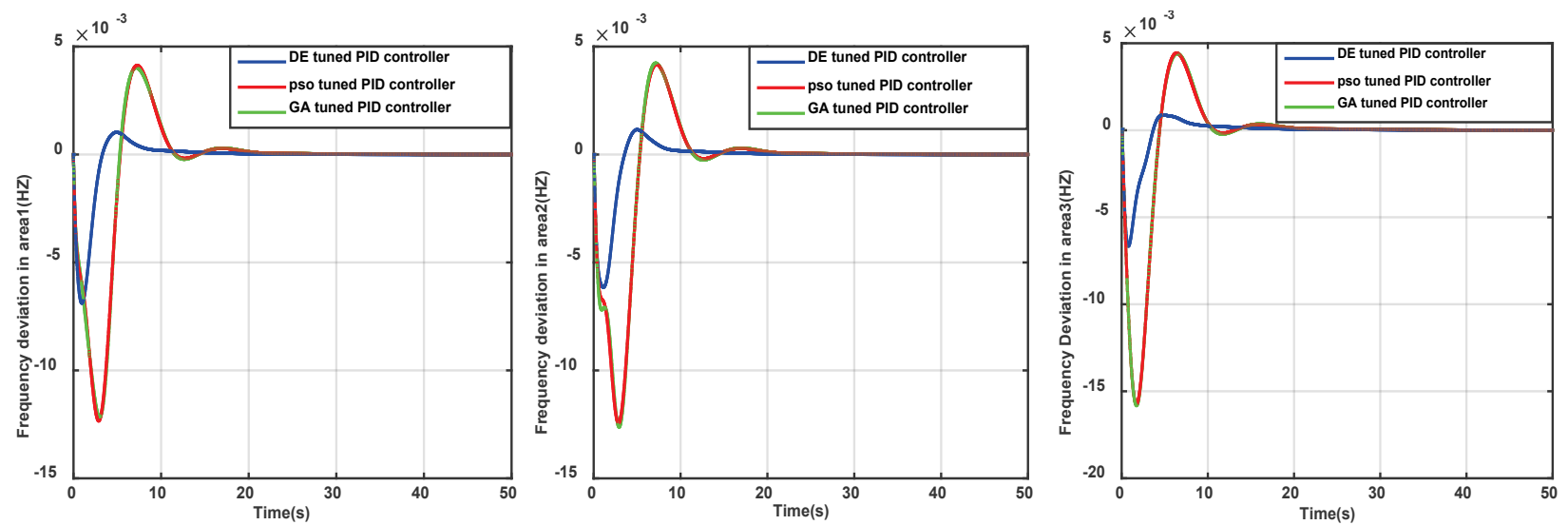

Figure 4 Dynamic response of the system frequency deviation
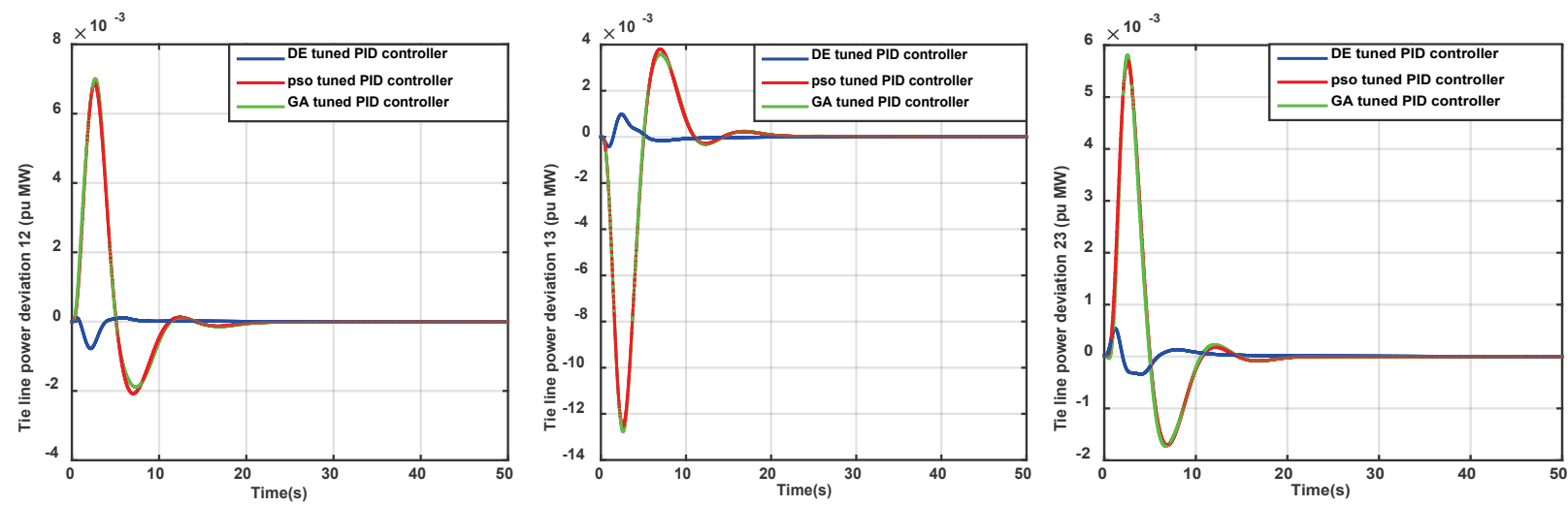

Figure 5 Dynamic response of tie line power deviation

Table 2 Power system parameter values

\begin{tabular}{|c|c|c|}
\hline Area 1: & Area 2: & Area 3: \\
\hline $\begin{array}{l}T_{g 1}=0.08 \mathrm{~s} \\
T_{t 1}=0.35 \mathrm{~s} \\
R_{1}=0.3333 \frac{\mathrm{Hz}}{\mathrm{pu}} \mathrm{MW} \\
k_{g 1}=1 \\
k_{t 1}=1 \\
T_{g 2}=0.875 \mathrm{~s} \\
T_{t 2}=0.375 \mathrm{~s} \\
k_{r 2}=0.3113 \\
T_{r 2}=10.6 \mathrm{~s} \\
R_{2}=0.32 \frac{\mathrm{Hz}}{\mathrm{pu}} \mathrm{MW} \\
k_{g 2}=k_{t 2}=1 \\
T_{g 3}=0.08 \mathrm{~s} \\
T_{t 3}=0.3 \mathrm{~s} \\
k_{r 3}=0.5 \\
T_{r 3}=10 \mathrm{~s} \\
R_{3}=0.33 \frac{\mathrm{Hz}}{\mathrm{pu}} \mathrm{MW} \\
k_{g 3}=k_{t 3}=1 \\
k_{p 1}=20 \frac{\mathrm{Hz}}{\mathrm{pu}} \mathrm{MW} \\
T_{p 1}=120 \mathrm{~s} \\
B_{1}=0.532 \frac{\mathrm{pu}}{\mathrm{MW}} \mathrm{Hz} \\
f=60 \mathrm{~Hz}\end{array}$ & $\begin{array}{l}T_{G H 4}=0.1 \mathrm{~s} \\
T_{R H 4}=10 \mathrm{~s} \\
T_{R S 4}=0.513 \mathrm{~s} \\
T_{W 4}=1 \mathrm{~s} \\
R_{4}=0.32 \frac{\mathrm{Hz}}{\mathrm{pu}} \mathrm{MW} \\
k_{g 4}=k_{t 4}=1 \\
T_{g 5}=0.075 \mathrm{~s} \\
T_{t 5}=0.38 \mathrm{~s} \\
R_{5}=0.2963 \frac{\mathrm{Hz}}{\mathrm{pu}} \mathrm{MW} \\
k_{g 5}=k_{t 5}=1 \\
k_{p 2}=20 \frac{\mathrm{Hz}}{\mathrm{pu}} \mathrm{MW} \\
T_{p 2}=120 \mathrm{~s} \\
B_{1}=0.495 \frac{\mathrm{pu}}{\mathrm{MW}} \mathrm{Hz} \\
f=60 \mathrm{~Hz}\end{array}$ & $\begin{array}{l}T_{g 6}=0.07 \mathrm{~s} \\
T_{t 6}=0.36 \mathrm{~s} \\
K_{r 6}=0.33 \\
T_{r 6}=10 \mathrm{~s} \\
R_{6}=0.289 \frac{\mathrm{Hz}}{\mathrm{pu}} \mathrm{MW} \\
k_{g 6}=k_{t 6}=1 \\
T_{G H 7}=0.015 \mathrm{~s} \\
T_{R H 7}=8.75 \mathrm{~s} \\
T_{R S 7}=0.1513 \mathrm{~s} \\
T_{W 7}=1.5 \mathrm{~s} \\
R_{7}=0.3077 \frac{\mathrm{Hz}}{\mathrm{pu}} \mathrm{MW} \\
k_{g 7}=k_{t 7}=1 \\
k_{p 3}=20 \frac{\mathrm{Hz}}{\mathrm{pu}} \mathrm{MW} \\
T_{p 3}=120 \mathrm{~s} \\
B_{3}=0.542 \frac{\mathrm{pu}}{\mathrm{MW}} \mathrm{Hz} \\
f=60 \mathrm{~Hz} \\
T_{12}=T_{23}=T_{13}=0.543 \\
\mathrm{pu} / \mathrm{H}\end{array}$ \\
\hline
\end{tabular}

Tab. 3 shows the amount of overshoot, undershoot and settling time in exchange of power system all three algorithms. The results show that the dynamic performance of DE algorithm is suitable.

\subsection{Controller Performance against Load Changes}

In order to evaluate the performance of the controller against possible load variation, the load of all areas changes from $-50 \%$ to $+50 \%$. Figs. 6 and 7 show the frequency deviation and tie-line power exchange between different areas respectively. The amount of overshoot, undershoot and settling time in various states of load changes for three algorithms is shown in Tabs. 4 and 5.

Results in Tabs. 4 and 5 clearly show that increment in rate of load, increases the measured values and the DE algorithm has more satisfactory performance in the case of load changes. The effect of reducing the amount of load up to $-50 \%$, settling time for the tie-line power exchange between different areas will be zero.

This shows that the controller proposed is well managed from the beginning and control deviations without any delay within the desired precision and show satisfactory performance. In the case of load reduction up to $-25 \%$, the settling time for $\Delta p_{\text {tie23 }}$ also has a similar situation. 
Table 3 Overshoot, undershoot and settling time for base case with PID controller using DE, PSO and GA algorithms

\begin{tabular}{|c|c|c|c|c|c|c|c|c|c|}
\hline \multirow{2}{*}{ Parameters } & \multicolumn{3}{|c|}{$\mathrm{DE}$} & \multicolumn{3}{|c|}{ PSO } & \multicolumn{3}{|c|}{ GA } \\
\hline & OS & US & ST & OS & US & ST & $\mathrm{OS}$ & US & ST \\
\hline$\Delta f_{1}$ & 0.00102 & -0.0068 & 6.96 & 0.0041 & -0.0122 & 10.79 & 0.004 & -0.0121 & 10.82 \\
\hline$\Delta f_{2}$ & 0.00115 & -0.00614 & 7.209 & 0.00415 & -0.0124 & 10.75 & 0.0042 & -0.0126 & 10.75 \\
\hline$\Delta f_{2}$ & 0.000818 & -0.0067 & 7.09 & 0.0043 & -0.0157 & 9.84 & 0.0043 & -0.0158 & 9.8 \\
\hline$\Delta P_{t i e 12}$ & 0.000113 & -0.00077 & 2.83 & 0.0068 & -0.00207 & 9.95 & 0.007 & -0.00188 & 10.16 \\
\hline$\Delta P_{t i e 13}$ & 0.00097 & -0.00041 & 3.44 & 0.0037 & -0.0125 & 10.28 & 0.00356 & -0.0127 & 10.35 \\
\hline$\Delta P_{t i e ~ 23}$ & 0.00051 & -0.00036 & 1.35 & 0.00567 & -0.00172 & 9.523 & 0.00578 & -0.00174 & 9.51 \\
\hline
\end{tabular}

Table 4 Overshoot, undershoot and settling time of $\Delta f_{1}, \Delta f_{2}, \Delta f_{3}$ for different loading conditions

\begin{tabular}{|c|c|c|c|c|c|c|c|c|c|c|}
\hline \multirow{2}{*}{ Controller } & \multirow{2}{*}{$\begin{array}{c}\text { Changes in load } \\
(\%)\end{array}$} & \multicolumn{3}{|c|}{$\Delta f_{1}$} & \multicolumn{3}{|c|}{$\Delta f_{2}$} & \multicolumn{3}{|c|}{$\Delta f_{3}$} \\
\hline & & OS & US & ST & OS & US & ST & OS & US & ST \\
\hline \multirow{4}{*}{$\mathrm{DE}$} & $-50 \%$ & 0.00051 & -0.0034 & 5.23 & 0.000574 & -0.00307 & 5.67 & 0.000409 & -0.0033 & 3.17 \\
\hline & $-25 \%$ & 0.00076 & -0.00515 & 6.37 & 0.00086 & -0.0046 & 6.63 & 0.00061 & -0.00502 & 6.37 \\
\hline & $+25 \%$ & 0.00128 & -0.0085 & 7.43 & 0.00143 & -0.0076 & 7.61 & 0.00102 & -0.0083 & 7.54 \\
\hline & $+50 \%$ & 0.00154 & -0.0103 & 7.83 & 0.00172 & -0.00921 & 7.92 & 0.00122 & -0.01005 & 8.01 \\
\hline \multirow{4}{*}{ PSO } & $-50 \%$ & 0.00206 & -0.0061 & 10.28 & 0.00207 & -0.00621 & 10.2 & 0.00219 & -0.00789 & 9.33 \\
\hline & $-25 \%$ & 0.00309 & -0.00924 & 10.6 & 0.00311 & -0.00932 & 10.53 & 0.00328 & -0.01184 & 9.62 \\
\hline & $+25 \%$ & 0.0051 & -0.01541 & 10.93 & 0.005196 & -0.0155 & 10.87 & 0.005475 & -0.01973 & 9.95 \\
\hline & $+50 \%$ & 0.00617 & -0.01849 & 11.03 & 0.006236 & -0.01865 & 10.96 & 0.00657 & -0.02368 & 10.05 \\
\hline \multirow{4}{*}{ GA } & $-50 \%$ & 0.002 & -0.00608 & 10.33 & 0.00211 & -0.0063 & 10.24 & 0.002175 & -0.00793 & 9.36 \\
\hline & $-25 \%$ & 0.003 & -0.0091 & 10.65 & 0.00317 & -0.0094 & 10.57 & 0.003263 & -0.0119 & 9.65 \\
\hline & $+25 \%$ & 0.005 & -0.01518 & 10.96 & 0.005285 & -0.01577 & 10.87 & 0.005438 & -0.01938 & 9.92 \\
\hline & $+50 \%$ & 0.006 & -0.01825 & 11.03 & 0.006342 & -0.01892 & 10.96 & 0.006526 & -0.02379 & 10.02 \\
\hline
\end{tabular}

Table 5 Overshoot, undershoot and settling time of $\Delta P_{\text {tie } 12}, \Delta P_{\text {tie } 13}$ and $\Delta P_{\text {tie } 23}$ for different loading conditions

\begin{tabular}{|c|c|c|c|c|c|c|c|c|c|c|}
\hline \multirow{2}{*}{ Controller } & \multirow{2}{*}{$\begin{array}{c}\text { Changes in load } \\
(\%)\end{array}$} & \multicolumn{3}{|c|}{$\Delta P_{\text {tie } 12}$} & \multicolumn{3}{|c|}{$\Delta P_{t i e 13}$} & \multicolumn{3}{|c|}{$\Delta P_{\text {tie } 23}$} \\
\hline & & OS & US & ST & $\mathrm{OS}$ & US & ST & OS & US & ST \\
\hline \multirow{4}{*}{$\mathrm{DE}$} & $-50 \%$ & 0.000056 & -0.00038 & 0 & 0.00048 & -0.00020 & 0 & 0.000259 & -0.00018 & 0 \\
\hline & $-25 \%$ & 0.000085 & -0.00057 & 2.58 & 0.00073 & -0.00031 & 3.14 & 0.00038 & -0.00027 & 0 \\
\hline & $+25 \%$ & 0.00014 & -0.00096 & 3.03 & 0.001222 & -0.00052 & 3.76 & 0.00064 & -0.00045 & 1.52 \\
\hline & $+50 \%$ & 0.00017 & -0.00116 & 3.14 & 0.00146 & -0.00062 & 4.08 & 0.00077 & -0.00054 & 4.4 \\
\hline \multirow{4}{*}{ PSO } & $-50 \%$ & 0.00343 & -0.00103 & 9.17 & 0.001898 & -0.00626 & 9.76 & 0.002836 & -0.00086 & 8.66 \\
\hline & $-25 \%$ & 0.00515 & -0.00155 & 9.67 & 0.002847 & -0.0094 & 10.1 & 0.004254 & -0.00129 & 9.23 \\
\hline & $+25 \%$ & 0.00858 & -0.00259 & 10.14 & 0.004745 & -0.01567 & 10.4 & 0.00709 & -0.00215 & 9.73 \\
\hline & $+50 \%$ & 0.0103 & -0.0031 & 10.26 & 0.00569 & -0.0188 & 10.49 & 0.008507 & -0.00258 & 9.85 \\
\hline \multirow{4}{*}{ GA } & $-50 \%$ & 0.0035 & -0.00094 & 9.35 & 0.001784 & -0.00637 & 9.83 & 0.002894 & -0.00087 & 8.66 \\
\hline & $-25 \%$ & 0.0052 & -0.0014 & 9.86 & 0.002676 & -0.00957 & 10.15 & 0.004341 & -0.0013 & 9.23 \\
\hline & $+25 \%$ & 0.00875 & -0.00235 & 10.33 & 0.004459 & -0.01595 & 10.45 & 0.007235 & -0.00217 & 9.69 \\
\hline & $+50 \%$ & 0.0105 & -0.00282 & 10.45 & 0.005351 & -0.01914 & 10.52 & 0.008682 & -0.00261 & 9.81 \\
\hline
\end{tabular}
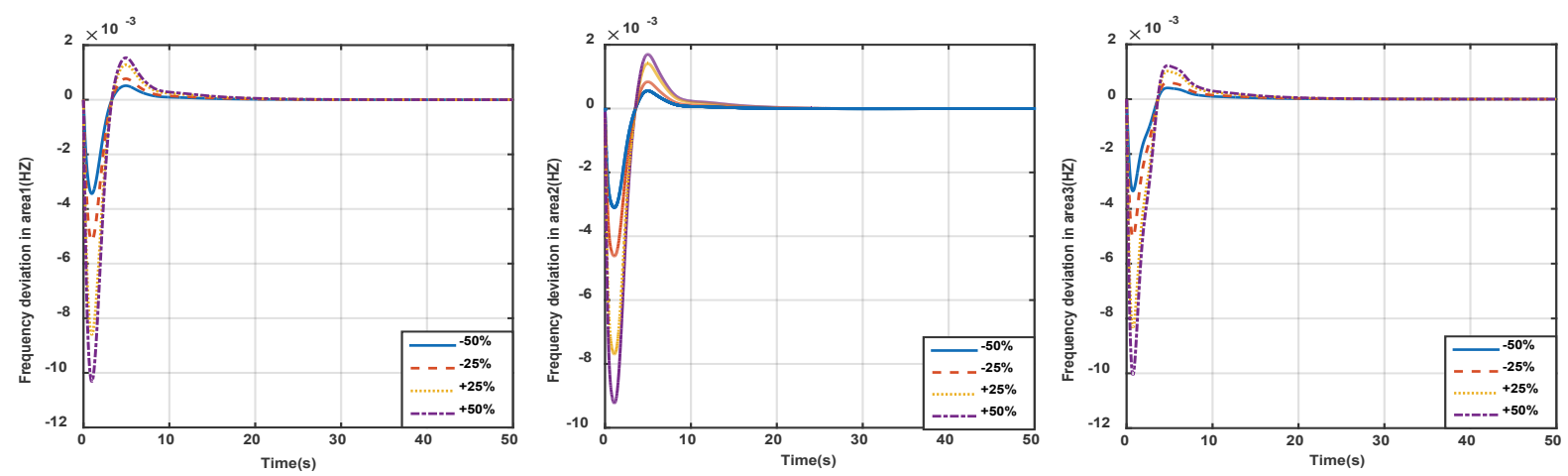

Figure 6 System response of frequency deviation for different loading changes

\subsection{Evaluation of Controller against Changes in System Parameters}

In order to further evaluate the performance of the proposed controller under various conditions, several system parameters such as $T_{t}$ (turbine time constant), $T_{r}$ (reheat time constant), $T_{G H}$ (hydro turbine speed governor main servo time constant), $T_{R S}$ (hydro turbine speed governer reset time), $T_{R H}$ (hydro turbine speed governer transient droop time constant) have been changed in the range of $-25 \%$ to $+25 \%$ compared to their nominal values by considering the coefficients of an optimal controller.

Important dynamic indices are overshoot, undershoot and settling time which are measured and tabulated in Tabs. 6 and 7. The results show that the values of the indices measured are in an acceptable range and close to the values of the parameters of the system. 

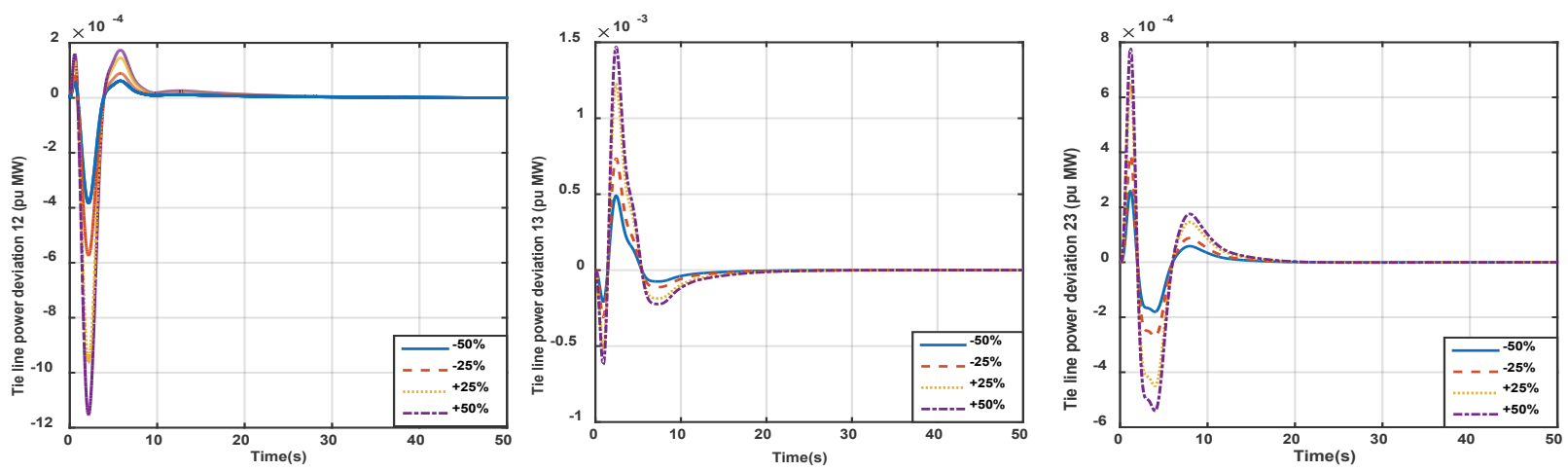

Figure 7 System response of tie-line power deviation for different loading changes

Table 6 Overshoot, undershoot and setting time of $\Delta f_{1}, \Delta f_{2}, \Delta f_{3}$ for different values of system parameters

\begin{tabular}{|c|c|c|c|c|c|c|c|c|c|c|}
\hline \multirow{2}{*}{$\begin{array}{c}\text { System } \\
\text { parameters }\end{array}$} & \multirow{2}{*}{$\begin{array}{c}\text { Changes in load } \\
(\%)\end{array}$} & \multicolumn{3}{|c|}{$\Delta f_{1}$} & \multicolumn{3}{|c|}{$\Delta f_{2}$} & \multicolumn{3}{|c|}{$\Delta f_{3}$} \\
\hline & & OS & US & ST & OS & US & ST & OS & US & ST \\
\hline \multirow{2}{*}{$T_{t}$} & $-25 \%$ & 0.00099 & -0.00629 & 7.3 & 0.00108 & -0.0057 & 7.46 & 0.00081 & -0.0059 & 7.3 \\
\hline & $+25 \%$ & 0.0011 & -0.0074 & 6.3 & 0.00147 & -0.00659 & 7.61 & 0.00156 & -0.0075 & 7.21 \\
\hline \multirow{2}{*}{$T_{r}$} & $-25 \%$ & 0.001 & -0.0068 & 6.65 & 0.00117 & -0.00611 & 7.03 & 0.0008 & -0.00659 & 6.94 \\
\hline & $+25 \%$ & 0.00102 & -0.0069 & 7.14 & 0.00113 & -0.00616 & 7.31 & -0.0082 & -0.0067 & 7,17 \\
\hline \multirow{2}{*}{$T_{G H}$} & $-25 \%$ & 0.00102 & -0.00688 & 6.93 & 0.00114 & -0.00612 & 7.19 & 0.00081 & -0.0067 & 7.07 \\
\hline & $+25 \%$ & 0.00103 & -0.0068 & 6.99 & 0.00115 & -0.0061 & 7.22 & 0.00082 & $\begin{array}{l}-0.0066 \\
\end{array}$ & $\overline{7.11}$ \\
\hline \multirow{2}{*}{$T_{R S}$} & $-25 \%$ & 0.00104 & -0.00682 & 7.03 & 0.00116 & -0.00617 & 7.23 & 0.00085 & -0.0066 & 7.15 \\
\hline & $+25 \%$ & 0.0010 & $\begin{array}{l}-0.0069 \\
\end{array}$ & 6.89 & 0.00113 & -0.00611 & 7.18 & 0.00077 & -0.0067 & 7.01 \\
\hline \multirow{2}{*}{$T_{R H}$} & $-25 \%$ & 0.00106 & -0.00707 & 6.38 & 0.00126 & -0.0063 & 6.43 & 0.00113 & -0.0073 & 7.20 \\
\hline & $+25 \%$ & 0.00090 & -0.00677 & 7.31 & 0.00105 & -0.00606 & 7.51 & 0.00082 & -0.0063 & 7.28 \\
\hline
\end{tabular}

Table 7 Overshoot, undershoot and setting time of $\Delta P_{\text {tie } 12}, \Delta P_{\text {tie } 13}$ and $\Delta P_{\text {tie } 23}$ for different values of system parameters

\begin{tabular}{|c|c|c|c|c|c|c|c|c|c|c|}
\hline \multirow{2}{*}{$\begin{array}{c}\text { System } \\
\text { parameters }\end{array}$} & \multirow{2}{*}{$\begin{array}{c}\text { Changes in } \\
\text { load }(\%)\end{array}$} & \multicolumn{3}{|c|}{$\Delta P_{\text {tie } 12}$} & \multicolumn{3}{|c|}{$\Delta P_{t i e 13}$} & \multicolumn{3}{|c|}{$\Delta P_{\text {tie } 23}$} \\
\hline & & OS & US & ST & OS & US & ST & OS & US & ST \\
\hline \multirow{2}{*}{$T_{t}$} & $-25 \%$ & $8.01 \times 10^{-5}$ & -0.00055 & 2.57 & 0.00070 & -0.00027 & 3.93 & 0.00043 & -0.00039 & 0 \\
\hline & $+25 \%$ & 0.00028 & -0.00109 & 2.89 & 0.00154 & -0.00058 & 3.1 & 0.00062 & -0.00051 & 2.66 \\
\hline \multirow{2}{*}{$T_{r}$} & $-25 \%$ & 0.000175 & -0.00083 & 2.80 & 0.00112 & -0.00037 & 3.30 & 0.00046 & -0.00039 & 0 \\
\hline & $+25 \%$ & 0.000105 & -0.000726 & 2.89 & 0.00088 & -0.00044 & 3.53 & 0.00055 & -0.00033 & 1.46 \\
\hline \multirow{2}{*}{$T_{G H}$} & $-25 \%$ & 0.000116 & -0.00078 & 2.85 & 0.00098 & -0.00042 & 3.44 & 0.00052 & -0.00036 & 1.36 \\
\hline & $+25 \%$ & 0.0001107 & -0.000763 & 2.86 & 0.00097 & -0.00041 & 3.47 & 0.00051 & -0.00035 & 1.31 \\
\hline \multirow{2}{*}{$T_{R S}$} & $-25 \%$ & $9.47 \times 10^{-5}$ & -0.000689 & 2.82 & 0.00092 & -0.00037 & 3.59 & 0.00051 & -0.00038 & 1.31 \\
\hline & $+25 \%$ & 0.000144 & -0.000859 & 2.89 & 0.00104 & -0.00046 & 3.32 & 0.00053 & -0.00036 & 1.35 \\
\hline \multirow{2}{*}{$T_{R H}$} & $-25 \%$ & 0.0002521 & -0.00126 & 3.27 & 0.00180 & -0.00077 & 3.44 & 0.00066 & -0.00055 & 2.75 \\
\hline & $+25 \%$ & 0.000113 & -0.00064 & 2.41 & 0.00066 & -0.00025 & 2.94 & 0.00045 & -0.00038 & 0 \\
\hline
\end{tabular}

\section{CONCLUSION}

In this paper, the design of an intelligent controller in interconnected large power system has been presented. An extensive analysis of proposed LFC system controller in the interconnected power system has been done when execution of the changes load demand and changes in system parameters are taken into account. Results clearly show that PID controller reaches to zero deviations in steady state in frequency and tie line power quickly.

In order to show superiority of PID designed controller using DE algorithm, the results of the Differential Evolution technique of parameters such as frequency and power tie line changes compared with the results of the PSO and GA algorithms. Results prove that DE algorithm has better overshoot, undershoot and settling time in all possible as compared to PSO and GA. Furthermore, the results of simulations show that the proposed algorithm is not affected by changes in load and uncertainty in the system parameters and the controller has satisfactory dynamic operation.

\section{REFERENCES}

[1] Prakash, S. \& Sinha, S. (2014). Simulation based neuro-fuzzy hybrid intelligent PI control approach in four-area load frequency control of interconnected power system. Applied Soft Computing, 23, 152-164. https://doi.org/10.1016/j.asoc.2014.05.020

[2] Padhan, D. G. \& Majhi, S. (2013). A new control scheme for PID load frequency controller of single-area and multi-area power systems. ISA transactions, 52(2), 242-251. https://doi.org/10.1016/j.isatra.2012.10.003

[3] Sahu, R. K., Panda, S., \& Rout, U. K. (2013). DE optimized parallel 2-DOF PID controller for load frequency control of power system with governor dead-band nonlinearity. International Journal of Electrical Power \& Energy Systems, 49, 19-33. https://doi.org/10.1016/j.jjepes.2012.12.009

[4] Chandrakala, K. V. \& Balamurugan, S. (2016). Simulated annealing based optimal frequency and terminal voltage control of multi source multi area system. International Journal of Electrical Power \& Energy Systems, 78, 823-829. https://doi.org/10.1016/j.ijepes.2015.12.026

[5] Anwar, M. N. \& Pan, S. (2015). A new PID load frequency controller design method in frequency domain through direct 
synthesis approach. International Journal of Electrical Power \& Energy Systems, 67, 560-569. https://doi.org/10.1016/j.ijepes.2014.12.024

[6] Nikmanesh, E., Hariri, O., Shams, H., \& Fasihozaman, M. (2016). Pareto design of load frequency control for interconnected power systems based on multi-objective uniform diversity genetic algorithm (muga). International Journal of Electrical Power \& Energy Systems, 80, 333-346. https://doi.org/10.1016/j.ijepes.2016.01.042

[7] Hota, P. \& Mohanty, B. (2016). Automatic generation control of multi source power generation under deregulated environment. International Journal of Electrical Power \& Energy Systems, 75, 205-214. https://doi.org/10.1016/j.ijepes.2015.09.003

[8] Khooban, M. H. \& Niknam, T. (2015). A new intelligent online fuzzy tuning approach for multi-area load frequency control: Self Adaptive Modified Bat Algorithm. International Journal of Electrical Power \& Energy Systems, 71, 254-261. https://doi.org/10.1016/j.jepes.2015.03.017

[9] Yesil, E. (2014). Interval type-2 fuzzy PID load frequency controller using Big Bang-Big Crunch optimization. Applied Soft Computing, 15, 100-112. https://doi.org/10.1016/j.asoc.2013.10.031

[10] Mosaad, M. I. \& Salem, F. (2014). LFC based adaptive PID controller using ANN and ANFIS techniques. Journal of Electrical Systems and Information Technology, 1(3), 212-222. https://doi.org/10.1016/j.jesit.2014.12.004

[11] Nayak, J. R., Pati, T. K., Sahu, B. K., \& Kar, S. K. (2015). Fuzzy-PID controller optimized TLBO algorithm on automatic generation control of a two-area interconnected power system. Paper presented at the Circuit, Power and Computing Technologies (ICCPCT 2015), International Conference on. https://doi.org/10.1109//CCPCT.2015.7159427

[12] Sekhar, G. C., Sahu, R. K., Baliarsingh, A., \& Panda, S. (2016). Load frequency control of power system under deregulated environment using optimal firefly algorithm. International Journal of Electrical Power \& Energy Systems, 74, 195-211. https://doi.org/10.1016/j.ijepes.2015.07.025

[13] Dhillon, S. S., Lather, J. S., \& Marwaha, S. (2015). Multi area load frequency control using particle swarm optimization and fuzzy rules. Procedia Computer Science, 57, 460-472. https://doi.org/10.1016/j.procs.2015.07.363

[14] Sahu, R. K., Sekhar, G. C., \& Panda, S. (2015). DE optimized fuzzy PID controller with derivative filter for LFC of multi source power system in deregulated environment. Ain Shams Engineering Journal, 6(2), 511-530. https://doi.org/10.1016/j.asej.2014.12.009

[15] Rocca, P., Oliveri, G., \& Massa, A. (2011). Differential evolution as applied to electromagnetics. IEEE Antennas and Propagation Magazine, 53(1), 38-49. https://doi.org/10.1109/MAP.2011.5773566

[16] Parmar, K. S., Majhi, S., \& Kothari, D. (2012). Load frequency control of a realistic power system with multi-source power generation. International Journal of Electrical Power \& Energy Systems, 42(1), 426-433. https://doi.org/10.1016/j.ijepes.2012.04.040

[17] Report, I. (1973). Dynamic models for steam and hydro turbines in power system studies. IEEE Transactions on Power Apparatus and Systems (6), 1904-1915. https://doi.org/10.1109/TPAS.1973.293570

[18] De Mello, F. \& Ahner, D. (1994). Dynamic models for combined cycle plants in power system studies. IEEE Transactions on Power Systems, 9(3). https://doi.org/10.1109/59.336085
Authors' contacts:

Alireza SINA, Faculty member of ACECR, Research scholar in UIET

Panjab University,

Sector 14, Chandigarh, Punjab 160014, India

sina@acecr.ac.ir

Damanjeet KAUR, Assistant Professor of Electrical \& Electronics Engineering, UIET Panjab University,

Sector 14, Chandigarh, Punjab 160014, India

djkb14@rediffmail.com 